\title{
LEAN AND BIM INTERACTION IN A HIGH RISE BUILDING
}

\author{
Frank Chuquín ${ }^{1}$, Cristhian Chuquín², and Romina Saire ${ }^{3}$
}

\begin{abstract}
Lean Design has been spreading its use in the AEC industry along with the emergence of Building Information Modelling (BIM).Those two methodologies; Lean and BIM are being implemented first independently and then together. as new means to deliver more efficient projects.

This paper researches some tools of Lean and BIM that permit a positive interaction by focusing on a case study related to a high rise building for residential use. Those tools are; from Lean Construction, set based design and value stream mapping. From BIM were used a 3D model and Integrated Concurrent Engineering (ICE) sessions. Also, the paper describes the interaction between those tools in the design phase and its impact in the construction stage.
\end{abstract}

\section{KEYWORDS}

Lean design, BIM, set based design, value stream, ice session.

\section{INTRODUCTION}

The construction industry in general is categorized as low productivity and riddled with inefficiencies. The construction sector is seen as one of the industries in which it uses intensive labor resources that open the doors to innovation and the implementation of new methodologies. According to Ghio V.(2000) in Lima the productivity levels were $27.9 \%$ of productive work, $36.3 \%$ of contributory work and $35.9 \%$ of non-contributory work. Later, in 2005 Morales N. and Galeas J. (2006) found this number slightly different: $30.4 \%$ of productive works, $44.2 \%$ of contributory works and $25.4 \%$ of non-contributory works. Then, the emergence of Lean Construction and Building Information Modeling as two innovative methodologies to address issues (productivity, inefficiencies) was gaining more adopters in the AEC industry on a global scale.

Lean concepts have been applied in the construction arena since the early 90s. Lean Construction is a new manner to deliver projects and a different manner of management. According to Koskela (2000), Lean Construction is "a way to design production systems to minimize waste of materials, time, and effort in order to generate the maximum possible amount of value". In Peru, Lean 'Construction was implemented first in the

1 Lecturer, Researcher at Construction Management \& Technology Research Group (GETEC), Pontifical Catholic University of Peru, Lima, Peru, frank.chuquin@ pucp.pe, orcid.org/0000-0001$\underline{8342-6602}$

2 Civil Engineer, Researcher at Construction Management \& Technology Research Group (GETEC), Pontifical Catholic University of Peru, Lima, Peru, chuquin.cr@pucp.edu.pe, orcid.org/0000-0002$\underline{4080-9600}$

3 Research Assistant at Construction Management \& Technology Research Group (GETEC), Pontifical Catholic University of Peru, Lima, Peru, rsairecanales@ gmail.com, orcid.org/0000-0002-2433-1301 
operation phase by using Last Planner ${ }^{\circledR}$ System (LPS), but little by little the Peruvian AEC community started implementing Lean Project Delivery System (LPDS) and in particular Lean Design through the use of different tools such as set based design, target value design and value stream mapping in the design phase.

In Peru, BIM started its implementation in 2010 and according to Murguia (2017) it was found that $24.5 \%$ of Peruvian projects implement BIM. Nevertheless, it is useful to keep in mind that not only technology is the necessary element in order to reach a successful implementation, but also processes, organizations and people. Also, Eastman et al.(2008) points out that BIM impacts the role and process of design in three different manners: the way conceptual design can be performed, the use of BIM for design and analysis of building systems and finally its use in developing construction-level information. In particular, the use of 3D models as a manner to influence conceptual design is also a way to improve visualization between different stakeholders.

Each of one, Lean Design and Building Information Modeling can be implemented independently as it was at the outset of using one of them. Sacks et al.(2010) states that Lean is "a conceptual approach to project and construction management and BIM is a transformative innovation technology". Nevertheless, the synergy that can be created by implementing both of them in the same project has been analyzed in different researches. Zhang et al.(2017) states that the interaction of BIM with Lean Design establishes better communication in the work team. Consequently the quality of coordination and efficiency in project design is increased. . Moreover, based on a study of the interaction between Lean Design and BIM in 64 projects, Herrera et al.(2021) concluded that the tool with the most interaction and positive impact on Lean design processes is the BIM tool "Integrated concurrent session".

\section{LITERATURE REVIEW}

\section{LEAN CONSTRUCTION}

It is a methodology based on the application of the principles of the Toyota production systems as it was stated by Sacks et al. (2010). Lean looks for the reduction of waste and variability while increasing value to the customer linked to a continuous improvement in each process. But nothing all the above can be reached if there is a lack of commitment and accountability. Moreover, Lean construction put at the center the respect for people which for Seed et al. (2018) play a pivotal role in the implementation of Lean Construction.

\section{LEAN DESIGN}

It is part of the Lean Project Delivery System (LPDS) which comprises five stages. Lean Design comes after project definition and before lean supply, lean assembly and use. Lean design comprises three processes: design concepts, process design and product design. LPDS aims to create a strong relationship between the roles of designers and builders.

\section{SET BASED DESIGN}

It is a tool of Lean Design in which the objective is to generate sets, different alternatives or solutions in order to evaluate them and to choose the most optimal according to the conditions of satisfaction or criteria. According to Hill et al. (2016) multiple options must be explored with the aim to choose an informed decision at the right time considering the 
last responsible moment. Each set of alternatives must be investigated and it is imperative to collect important information in order to support a decision.

\section{VALUE STREAM MAPPING}

This tool permits to map the generation of value, waste and countermeasures when it is analyzed in a particular process. According to Seed et al.(2018) "a value stream mapping includes both material and information flows, decision points, handoffs and interaction between systems". This tool encourages teams to evaluate the entire value stream by evaluating the value of each step and optimize the entire process through value stream mapping. This tool gives the opportunity of understanding the actual state of the process, this requires the input of all participants in the process.

\section{BUILDING INFORMATION MODELLING (BIM)}

According to the National Building information Modeling Standard (NBIMS), BIM is "an improved planning, design, construction, operation, and maintenance process using a standardized machine-readable information model for each facility, new or old, which contains all appropriate information created or gathered about that facility in a format useable by all throughout its lifecycle". Moreover, Eastman et al. (2008) defines BIM as "a modelling technology and associated set of processes to produce, communicate, and analyze building models". Those building models (digital representation through parametric objects) are composed by components that contain data in a consistent, non redundant, and coordinated manner.

\section{INTEGRATED CONCURRENT SESSION (ICE)}

Eastman et al. (2008) pointed out that ICE session is a collaborative work that involves different stakeholders such as: design team, engineering-technical specialists and consultants. The same authors states that ICE is "a special integration event consisting of three elements: product and project performance metrics, BIM + simulation, and process design. It is a problem-solving technique that looks for speeding up solutions considering different points of view. This design reviews are set in an I-room where stakeholders discuss aspects of the design on large screens. Moreover, by including ICE sessions in the design schedule when important decisions are made, it is possible to accelerate the evaluation of different alternatives.

\section{PROBLEM}

It is unknown to what extent those interactions between Lean principles and BIM functionalities create relevant positive or negative interactions that can be clearly understandable in terms of benefits and cost for practitioners in the AEC industry. According to Sacks et al.(2010) there are 56 interactions between Lean principles and BIM functionalities that could be analyzed in detail.

\section{HYPOTHESIS}

Four Lean and BIM tools (set based design, value stream mapping, a 3D model, and integrated concurrent sessions) were implemented with the hypothesis that these tools would provide a positive interaction since they would address problems earlier and facilitate the reduction of restrictions (i.e. less requests for information and fewer claims) in the construction phase. 


\section{METHODOLOGY}

The approach of this research is divided in two stages: design and construction. Figure 1 shows the steps and components in each stage. In the design process it is planned to implement four tools: value stream mapping, set based design, 3D model and ICE sessions. Then, training is necessary for those stakeholders who are unfamiliar with these tools.

At the end of the design process a qualitative analysis is done through surveys to the stakeholders involved. Also, a quantitative analysis about the results reached with the four tools at the design stage is made, each interaction is analyzed. There were two interactions analyzed: a) value stream mapping and ICE sessions and b) set based design and 3D model.

In the construction stage, two types of information are collected: requests of information and claims. That information is categorized and the ones which are linked to design is described in detail and a quantitative analysis is made using two metrics: a) number of RFI (related to design and b) claims (related to design).

The research period took from the design phase until the handover of the infrastructure to the final client. Then, the exact time frame for the design phase was 6 months and 12 months for the construction phase, so we data collection took 18 months.

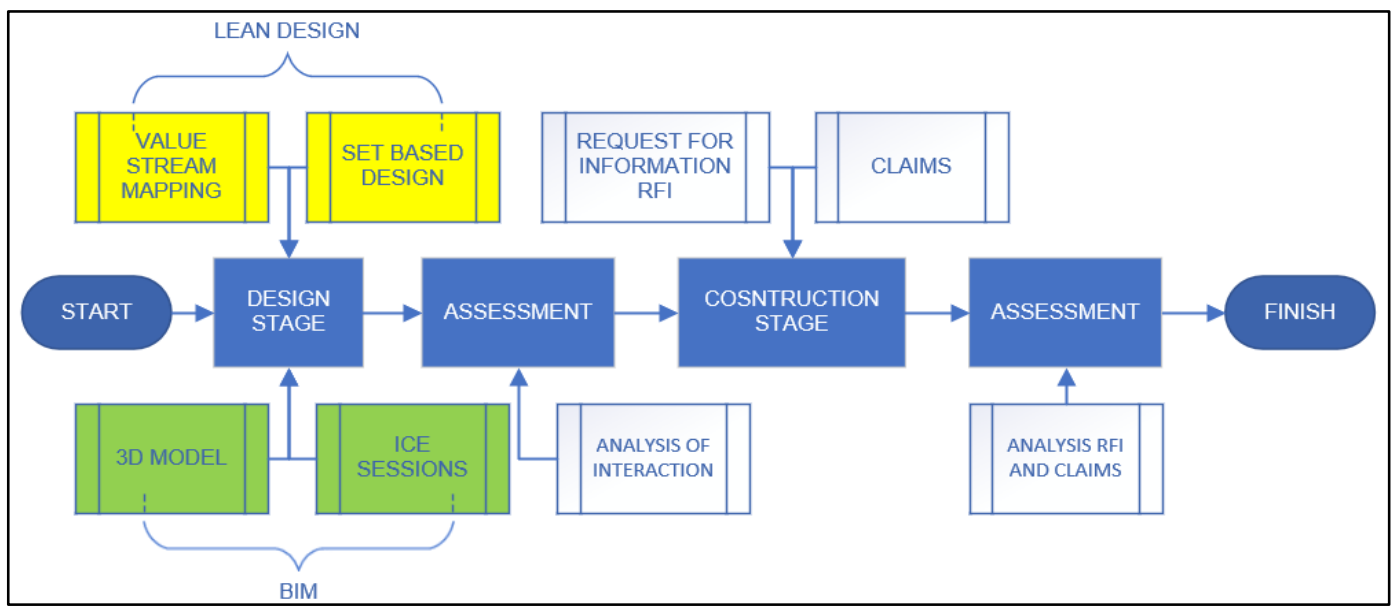

Figure 1: methodology implemented

\section{RESULTS}

\section{VSM AND ICE SESSIONS}

The involvement of each of the participants (architect, structural engineer, electrical engineer and plumbing engineer) were relevant for the construction of the entire value stream mapping.. It is important to highlight that as part of the flow process it was incorporated ICE sessions as part of the mapping.

The VSM permits to analyze each step in the flow. One result was that stakeholders paid close attention to one section of the entire VSM. This section is the one that shows more interaction between architects and structural engineers at the beginning of the design process. Figure 2 shows this interaction. In this first section, it is important to get the preliminary design in accordance with the pre dimensioning of different structural elements. It must be highlighted how the work of each other interacts and how they are involved in an ICE session. Different aspects are addressed in this ICE session such as: 
height of the beams, thickness of the slabs as well as lengths and thickness of shear walls and columns. This stage finalizes with the approval of the preliminary design (predimenionsing) and an architecture update.

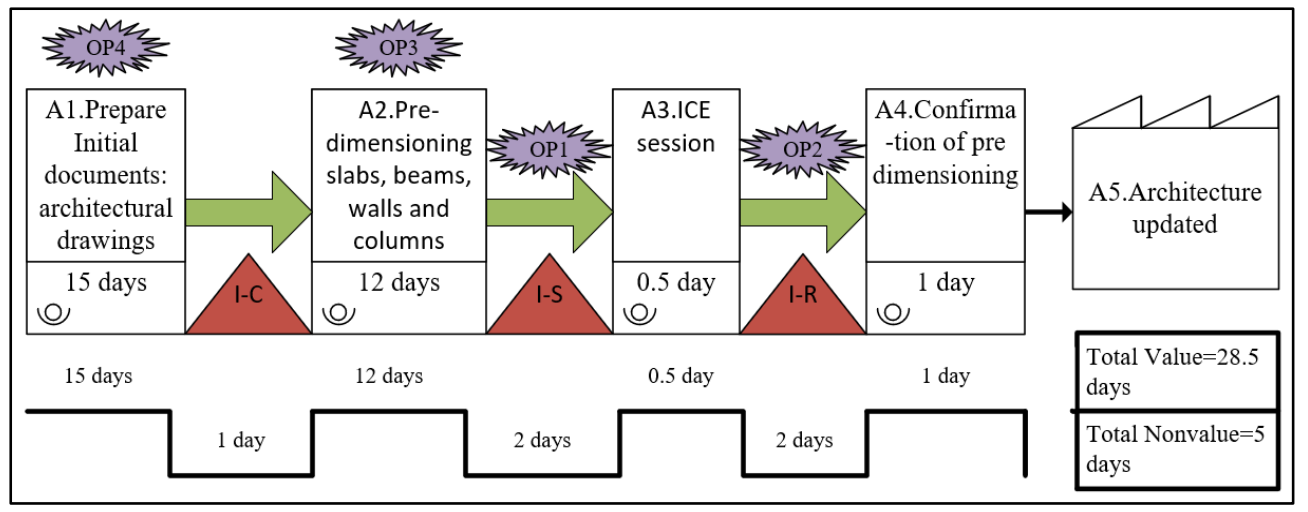

Figure 2: Actual VSM-section 1.

In this first section, the total time of value activities is 28.5 days and the total time of non value activities is 5 days. Four opportunities for improvement were detected. OP1: 2 business days takes to arrange an ICE session. OP2: the proposal from the structural engineer about pre-dimensioning is assessed by the architect in 2 business days. OP3: pre dimensioning takes 12 business days by structural engineer. OP4: architect takes 15 business days in preparing preliminary architectural designs and to have ready the geotechnical study.

Once the actual state is graphed in Figure 2 and stakeholders understand the value chains. A realistic and future scenario is discussed and Figure 3 shows the corresponding value stream mapping of the analyzed section.

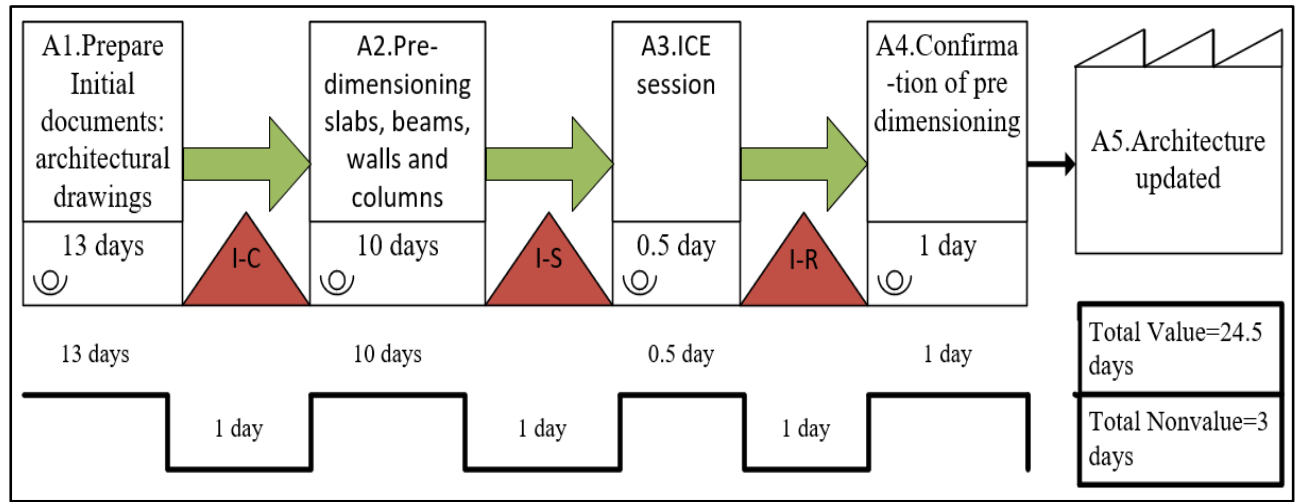

Figure 3: New and committed VSM-Section 1.

The design team was committed to this new value stream mapping (Figure 3) and they finally met the times. In this VSM, the total value time of the value activities is 24.5 days, which means a 14\% reduction compared to the former VSM (Figure 2). The reduction in duration of activity 1 (A1) and activity 2 (A2) was the cause of that time saving. Moreover, the total time of non value activities is 3 days, which means a reduction of $40 \%$ compared to the former VSM.

There was a second section of the VSM that was analyzed in an ICE session. This second section starts with the updated architecture (the output in section 1) which triggers the following structural design processes: slab design, seismic analysis, beams design, shear wall design, columns design and foundation design. In this flow process an ICE 
session is scheduled. This section deals with issues such as: clash detection and value engineering.

At the end of the design process a survey was done to those stakeholders involved in the implementation of these two tools (VSM and ICE), 70\% of participants mentioned that those tools were useful for their work and they are keen on applying them in future projects. Also, $90 \%$ of people pointed out that training was the most critical factor for success.

\section{SET BASED DESIGN AND 3D MODEL}

As part of the implementation of lean design tools, set based design was used. There were three different alternatives for the foundation of the building. This happened because adequate bearing capacity of the soil is reached at a great depth. The alternatives were:

Option 1: It is to use a mixture of simple spread footing with strap footing with the disadvantage that the length of the vertical elements (columns and shear walls) have to increase in order to make it possible for footings to reach the ground with enough bearing capacity.

Option 2: It is to implement micro piles as foundation in order to reach the appropriate soil with enough bearing capacity.

Option 3: it is to include a semi-basement floor. By adding a floor the level of the last basement is lowered. This inclusion decreases the length of columns and shear walls. Then, the foundation is located in a soil with appropriate bearing capacity.

A 3D model (Figure 4) helps stakeholders to deeply understand the implications of each alternative.

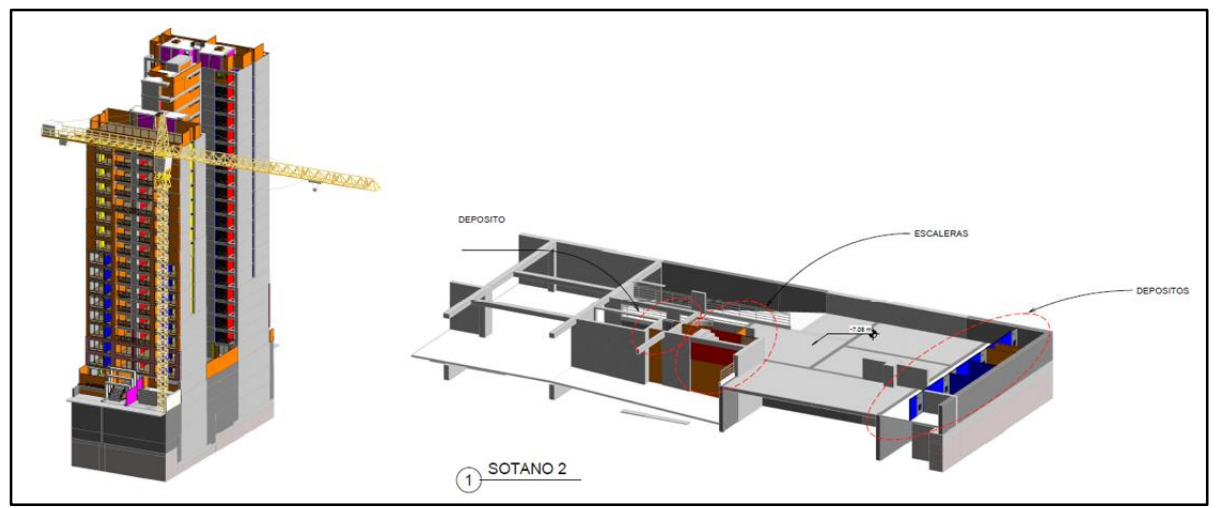

Figure 4: 3d model (left) and lower basement (right)

Those three alternatives were analyzed in terms of costs, benefits and duration (time of execution). Table 1 shows the different options and the criteria taken into account for the selection one.

Table 1: Comparison between different options

\begin{tabular}{cccc}
\hline Category & Option 1 & Option 2 & Option 3 \\
\hline Cost $\$$ & 53,731 & 41,791 & 150,775 \\
Benefits $\$$ & 0 & 0 & 104,000 \\
Net Cost & $-53,731$ & $-41,791$ & $-46,775$ \\
Duration (days) & 14 & 21 & 21 \\
\hline
\end{tabular}


Finally, the stakeholders involved found that the third alternative could give an advantage over the others. This is because, in this option, there is the opportunity to generate two new apartments for selling (the row of benefits in the table 1). Then, the third option was selected because it gives a net cost better than option 1, which means a $12.9 \%$ reduction in cost. Even though option 3 costs $10.7 \%$ more than option 2, this opportunity to have more area to sell (two new apartments) outweigh option 2 from the business point of view of the decision makers.

At the end of the design process a survey was done to those stakeholders involved in the implementation of these two tools (SBD and 3D model BIM), 50\% of participants mentioned that those tools were useful for their work and they are keen on applying them in future projects. Also, $100 \%$ of people pointed out that training and technology were the most critical factor for success.

\section{REQUEST FOR INFORMATION AT CONSTRUCTION PHASE}

Once the design had finished, the construction phase started and during this period some requests for information (RFI) were generated by the contractor for different circumstances and moments. Then, those RFI were collected and analyzed. Four types of categories were considered: scope change, queries, design issues, and clashes. The description of each one is:

Scope changes: An instruction from the owner about changes in the scope generates doubts in the contractor. Then, an RFI was issued for details.

Queries: The contractor issued an RFI because it needed clarification or it was difficult to understand the specification by any member of the contractor's team.

Design issues: An error in the design and/or specifications was found by the contractor and a RFI was issued in order to solve the problem.

Clashes: The designs of different specialities showed inconsistencies and incompatibilities. Then, an RFI was issued.

The following Table 2 shows the quantity and percentage for each category of RFI for the case presented in this paper (project 1) and historical data from a previous project (project 2).

Table 2: RFI by category for project 1 and project 2

\begin{tabular}{|c|c|c|c|c|}
\hline \multirow[b]{2}{*}{ Category } & \multicolumn{2}{|c|}{$\begin{array}{c}\text { Project } 1 \text { (Lean and BIM } \\
\text { interaction) }\end{array}$} & \multicolumn{2}{|c|}{$\begin{array}{c}\text { Project } 2 \text { (withouth Lean and } \\
\text { BIM implementation) }\end{array}$} \\
\hline & Quantity & Percentage & Quantity & Percentage \\
\hline $\begin{array}{l}\text { Scope } \\
\text { change }\end{array}$ & 47 & $27 \%$ & 52 & $23 \%$ \\
\hline Queries & 56 & $32 \%$ & 62 & $27 \%$ \\
\hline Design issues & 17 & $10 \%$ & 32 & $14 \%$ \\
\hline Clashes & 54 & $31 \%$ & 81 & $36 \%$ \\
\hline Total & 174 & $100 \%$ & 227 & $100 \%$ \\
\hline
\end{tabular}

As it is shown in table 2, there are $174 \mathrm{RFI}$ in total in project 1 which means $23.3 \%$ of reduction from project 2 . The ones that are design related are the categories: design issues and clashes that represent $10 \%$ and $31 \%$ respectively in project 1 . Those two categories sum up 71 RFI in total which represents $37.1 \%$ of reduction from project 2. 
An analysis of the claims presented by the contractor in this case study (project 1) was made. Table 3 shows quantities and costs of those claims.

Table 3: Claims by category for project 1 .

\begin{tabular}{ccccc}
\hline Category & $\begin{array}{c}\text { Claims } \\
\text { Quantity }\end{array}$ & $\begin{array}{c}\text { Claims } \\
\text { Percentage }\end{array}$ & $\begin{array}{c}\text { Claims Cost } \\
\mathbf{\$}\end{array}$ & $\begin{array}{c}\text { Claims Cost } \\
\text { Percentage }\end{array}$ \\
\hline Scope change & 20 & $22 \%$ & 26.124 & 295 \\
Queries & 22 & $50 \%$ & 15.386 & $17 \%$ \\
Design issues & 45 & $24 \%$ & 47.982 & $53 \%$ \\
Clashes & 3 & $3 \%$ & 1.186 & $1 \%$ \\
\hline TOTAL & $\mathbf{9 0}$ & $\mathbf{1 0 0 \%}$ & $\mathbf{9 0 . 6 7 9}$ & $\mathbf{1 0 0} \%$ \\
\hline
\end{tabular}

As it is shown in table 3, there are 90 claims in total in the case study (project 1). The ones that are design related are the categories: design issues and clashes that represent $24 \%$ and $3 \%$ respectively. Those two categories sum up 48 claims. Nevertheless, in terms of cost those two categories represent $54 \%$ of the total claims cost.

\section{DISCUSSION}

The results show a positive interaction between those four tools implemented in the design stage. Participants found useful tools such as VSM and Ice sessions because they had the opportunity to see the changes that occurred in the design process by reducing the total time of value and non value activities.

In the case of SBD and a 3D model there are less people interested in replicating the experience. A plausible explanation is related to the demand for knowledge in technology that is necessary in this interaction and the resistance to change by senior engineers with more than 20 years of experience in the industry. The design teams had $60 \%$ of participants with a seniority level.

A critical factor pointed by participants in the survey at the end of the design stage was training and technology. Workshops were done not only for staff personnel, but also for engineers of other companies (structural, electrical and plumbing engineer) that integrated the design team.

About the results at the end of the construction stage, they show a reduction in the number of RFI in the case study compared to project 2, which follows a traditional approach (without lean and bim). Even though this reduction is $37.1 \%$, it is still not significant. On top of that, the total cost of claims associated with design represents $54 \%$ of the total cost. An explanation of those results at the end of the construction stage could be the fact that the company is starting with the implementation of lean and bim tools in their projects and it is expected to gain more experience applying the tools in next projects.

\section{CONCLUSIONS}

The Lean and BIM tools used in the design stage support the interaction found by Sacks et al. (2010). In particular all four tools (VSM, SBD, 3D model and ICE session) demonstrate the existence of the positive interaction between the lean principle: "decide by consensus, consider all options" and the BIM functionality "visualization of form". Nevertheless, the findings in this case study suggest another new interaction between the lean principle "focus on concept selection" with the BIM functionality "visualization of 
form". This interaction is not registered in the matrix shown by Sacks et al. (2010). In this new positive interaction, set based design and a 3D model plays a pivotal role because a better understanding of different design alternatives early in the design phase can be reached if a model is shown to the decision makers.

Also, a change management strategy is necessary for getting better results. This strategy must include training sessions for the design team. This is because training is a critical factor for design improvement and for maintaining changes in the organization.

As a limitation of the paper, it will be necessary to collect more data from case studies in order to enrich the knowledge in this area.

\section{ACKNOWLEDGMENTS}

We would like to thank in advance all participants in this case study from designers, specialists, project manager and design manager. We would also like to thank the openness of the real estate company and its desire to achieve excellence.

\section{REFERENCES}

Eastman, C., Teicholz, P., Sack, R. and Liston, K.(2008). "BIM Handbook: A guide to building information modeling for owners, managers, designers, engineers, and contractors". John Wiley \& Sons, Inc. New Jersey.

Ghio, V.(2000). "Productividad en obras de construcción: Diagnóstico, crítica y propuesta". Fondo Editorial de la Pontificia Universidad Católica del Perú. Lima, Perú.

Hill, K., Copeland, K., Pikel, C. (2016). "Target Value Delivering: Practitioner guidebook to implementation", Lean Construction Institute, Virginia, USA.

Koskela, L. (2000). "An exploration towards a production theory and its application to construction". D. Tech. Helsinki University of Technology. Espoo.

Morales, N. and Galeas J.(2006). "Diagnóstico y evaluación de la relación entre el grado de industrialización y los sistemas de gestión con el nivel de productividad en obras de construcción". Pontificia Universidad Católica del Perú, Lima, Perú.

Murguía, D. (2017). "Estudio de adopción BIM en Lima-Perú". Pontificia Universidad Católica del Perú, Lima. Perú.

Herrera, R., Mourgues, C., Alarcon L. and Pellicer, E. (2021) "Analyzing the Association between Lean Design Management Practices and BIM Uses in the Design of Construction Projects", Journal of Construction engineering and Management. ASCE

Sacks, R., Koskela, L., Dave, B. and Owen, R.(2010). "Interaction of Lean and Building Information Modeling in Construction", Journal of Construction Engineering and Management. Vol. 136, No 9, September 1, 2010.

Seed, W. et al. (2018). "Transforming Design and Construction: A Framework for Change", Lean Construction Institute, Virginia, USA.

Zhang X., Azhar S., Nadeem A. \& Khalfan M. (2017). "Using Building Information Modelling to achieve Lean principles by improving efficiency of work teams", International Journal of Construction Management. Vol. 33, No 6, 740-752. 